\title{
Compendial Method
}

National Cancer Institute

\section{Source}

National Cancer Institute. Compendial Method. NCI Thesaurus. Code C96102.

Standardized methods and specification testing for generic pharmaceutical raw materials and finished products. 